\section{CICLISMO URBANO COMO DIREITO HUMANO À MOBILIDADE ATIVA NA CIDADE DE SÃO PAULO}

\author{
URBAN BICYCLING AS A HUMAN RIGHT TO ACTIVE MOBILITY IN THE CITY OF \\ SAO PAULO
}
CICLISMO URBANO COMO DERECHO HUMANO A LA MOVILIDAD ACTIVA EN LA CIUDAD DE SÃO PAULO

\author{
Leandro Dri Manfiolete Troncoso*, Rodolfo Franco Puttini*, \\ Luiz Gonçalves Junior**, Sérgio Alejandro Toro-Arévalo***
}

\begin{abstract}
Palavras chave:
Ciclismo.

Direitos humanos.

Educação.

Política pública.

Resumo: 0 ciclismo urbano é um fenômeno recente valorizado como alternativa ao transporte motorizado individual. $\mathrm{O}$ objetivo do artigo é compreender os processos educativos do ciclismo urbano, decorrentes da prática social do cicloativismo atuante na cidade de São Paulo. Realizamos quatro entrevistas com pessoas que habitam e se locomovem de bicicleta neste município. A trajetória metodológica seguiu a modalidade fenômeno situado da Fenomenologia. Na construção dos resultados, as unidades de significado: a) luta por reconhecimento no direito de fruir o território em bicicleta; b) solidariedade com outrem no compartilhamento seguro das vias públicas; c) percepção do entorno e d) comunicação do movimento cicloativista resultaram na categoria "Pedalar como direito humano à mobilidade ativa na cidade". Constatamos que, apesar do processo legítimo de diálogo, as demandas cicloativistas são pouco incorporadas às políticas públicas de mobilidade urbana por falta de representação institucional.
\end{abstract}

Keywords:

Bicycling.

Human Rights.

Education.

Public Policy.

Palabras clave:

Ciclismo.

Derechos Humanos.

Educación.

Política Pública.

Abstract: Urban bicycling is a recent phenomenon valued as an alternative to individual transportation by motor vehicles. This article looks into the educational processes of urban bicycling that resulted from the social practice of bicycling activism in the city of Sao Paulo. We conducted four interviews with people who live and use bicycles in that city. The methodological trajectory followed Phenomenology's view on situated phenomena. In the construction of results, the units of meaning a) fight for recognition of the right to enjoy territory by bicycle; b) solidarity with others in safe sharing of public roads; $c$ ) perception of the environment; and d) communication of the bicycling activist movement resulted in the category "Pedaling as a human right to active mobility in the city". We found that, despite the legitimate process of dialogue, the demands of bicycling activism are not highly incorporated into public policies for urban mobility due to lack of institutional representation.

Resumen: El ciclismo urbano es un fenómeno reciente valorado como alternativa al transporte motorizado individual. El objetivo del artículo es comprender los procesos educativos del ciclismo urbano, derivados de la práctica social del cicloactivismo que actúa en la ciudad de São Paulo. Realizamos cuatro entrevistas con personas que habitan y se desplazan en bicicleta en este municipio. La trayectoria metodológica siguió la modalidad fenómeno situado, de la Fenomenología. En la construcción de los resultados, las unidades de significado: a) lucha por reconocimiento en el derecho de disfrutar del territorio en bicicleta; b) solidaridad con otros al compartir de manera segura las vías públicas; c) percepción del entorno y d) comunicación del movimiento cicloactivista, resultaron la categoría "Pedalear como derecho humano a la movilidad activa en la ciudad". Constatamos que, a pesar del proceso legítimo de diálogo, las demandas cicloactivistas son poco incorporadas a las políticas públicas de movilidad urbana por falta de representación institucional.
*Universidade Estadual Paulista "Júlio de Mesquita Filho" (UNESP). Rio Claro, SP, Brasil.

E-mail: leandro_dri@ hotmail.com; puttini@fmb.unesp.br

**Universidade Federal de São Carlos (UFSCar). São Carlos, SP, Brasil. E-mail: luizgj7@gmail.com

***Universidad Austral de Chile. Valdívia, Chile.

E-mail: seatoro@gmail.com

Recebido em: 16-05-2018 Aprovado em: 15-09-2018

DOI https://doi.org/10.22456/1982-8918.82908 (c) (1) (8) Licence 


\section{INTRODUÇÃO}

São Paulo (Brasil) é historicamente uma das cidades protagonistas do ciclismo urbano no continente sul-americano. Duas personagens emblemáticas marcam aspectos simbólicos do cicloativismo com significados distintos na reivindicação do uso da bicicleta na vida social.

Afirmamos que a primeira cicloativista, Veridiana da Silva Prado, desde o final do século XIX, foi uma aristocrata militante na cidade de São Paulo. Enquanto o primeiro velódromo do mundo fora construído em 1890 na cidade de Paris (França), em 1895, Veridiana Prado construiu o Velódromo Paulista, primeiro no Brasil, local promotor de provas de ciclismo desportivo para cidadãos e operários (SOUZA, 2016). Essa construção propiciou um movimento civil organizado representado por clubes ciclísticos, levando em conta a bicicleta como referência de veículo particular disponível para a população na época (GAMBETA, 2013).

O segundo aspecto simbólico do cicloativismo com significados distintos na reivindicação do uso da bicicleta está situado na atualidade, com o ciclismo urbano partindo da discussão pública, porém, restrito à perspectiva do transporte motorizado individual (COLVILLEANDERSEN, 2018). Nesse contexto, Fernando Haddad, prefeito municipal (2013-2016), foi 0 responsável pela reformulação do Plano Diretor Estratégico (PDE) em conjunto com o Plano de Mobilidade Urbana (PlanMob) (SÃO PAULO, 2015), cujas diretrizes passam a privilegiar a construção de infraestrutura cicloviária nos eixos de transporte coletivo, "locais prioritários para a otimização da terra urbana passando a qualificar a vida humana na escala de bairro pelo consequente desestímulo ao uso do automóvel" (SÃO PAULO, 2014). Esses compromissos institucionais refletiram na implantação de mais de 400 quilômetros de infraestrutura cicloviária no município.

Estamos a par desses dois sentidos do ciclismo urbano que surgem de duas personagens emblemáticas: uma que iniciou no final do século XIX o sentido desportivo e outra atual protagonista na promoção da participação cidadã para o uso cotidiano da bicicleta nas vias públicas.

O objetivo deste artigo foi compreender os processos educativos do ciclismo urbano decorrentes da prática social do cicloativismo atuante na cidade de São Paulo. As categorias "processos educativos" e "prática social" referem-se ao âmbito dos estudos acadêmicos na área da Educação, cuja discussão teórica está aplicada ao contexto do movimento cicloativista. A ideia de processos educativos implica assumir a perspectiva de ensino-aprendizagem como exercício cidadão de participação democrática para autonomia das pessoas nos espaços da cidade (FREIRE; FAUNDEZ, 2012), ou seja, o conhecimento gerado com outros ciclistas urbanos durante o tempo de trabalho que compartilham a percepção do descaso institucional na gestão da política pública. Já a noção de prática social nos auxilia a interpretar as interações entre indivíduos no ambiente social com o propósito de produzir bens e transmitir valores voltados para a formação pessoal na vida em sociedade (OLIVEIRA et al., 2014) com a finalidade da agenda cicloativista em compreender a partir da bicicleta na via pública, uma mudança de mentalidade sobre o planejamento urbano.

Os sujeitos da pesquisa assinaram o Termo de Consentimento Livre e Esclarecido (TCLE) antes das entrevistas nos locais de trabalho, autorizando a publicação com seus nomes reais. $\mathrm{O}$ estudo foi aprovado pelo Comitê de Ética em Pesquisa com Seres Humanos do Instituto de Biociências de Rio Claro, Universidade Estadual Paulista "Júlio de Mesquita Filho" (IBRC-UNESP), registro CAAE 43889115.1.0000.5465, conforme resolução 466/12 do 
Conselho Nacional de Saúde (CNS) (BRASIL, 2012a). A pesquisa contou com apoio financeiro da Coordenadoria de Aperfeiçoamento de Pesquisa em Ensino Superior (CAPES) através da bolsa de mestrado institucional, processo 14781412.

\section{METODOLOGIA}

Optamos pela pesquisa qualitativa fenomenológica na modalidade fenômeno situado (BICUDO; ESPÓSITO, 1997; BICUDO, 2011; MARTINS; BICUDO, 1989).

Bicudo (2011) considera fenômeno situado primeiramente a posição do pesquisador que, ao conhecer suas observações empíricas, carrega experiências vivenciadas como ponto de partida. $O$ fenômeno está situado quando o sujeito pesquisador e os sujeitos pesquisados ambos se encontram imersos no contexto estudado e, dessa forma, a trajetória metodológica passa a ser guiada em torno do desejo de compreensão em convivência com outras pessoas ligadas ao fenômeno, atribuindo significados. Para Bicudo e Espósito (1997), esta abordagem de pesquisa qualitativa segue uma perspectiva filosófica:

[‥] as descrições e agrupamentos dos fenômenos estão diretamente baseados nas descrições dos sujeitos, os dados são tratados como manifestações dos fenômenos estudados, o objeto da investigação é coletar descrições e trabalhar a essência do fenômeno individual através das descrições obtidas (MARTINS; BICUDO,1989, p.30).

Situado o fenômeno da nossa pesquisa, centramos na atualidade da reivindicação no uso da bicicleta diante da concepção estruturante com a formação de um ambiente dialógico entre organizações civis do ciclismo urbano entre canais de comunicação (blogs) nas redes sociais (ZUGE JUNIOR, 2015).

Vemos a Associação dos Ciclistas Urbanos de São Paulo (Ciclocidade) ${ }^{1}$, criada no ano de 2009, como essencial para nossa pesquisa. Essa entidade surge como representativa da sociedade civil e, daquele contexto, passa a estabelecer diálogo institucional com a gestão pública (CICLOCIDADE, 2018). Dada a diversidade dos atores sociais envolvidos no movimento social cicloativista na cidade de São Paulo, foram realizadas 16 entrevistas com sujeitos ligados a essa associação, tendo como critérios de seleção a condição de ser ciclista urbano como forma de mobilidade ativa, identificar-se como cicloativista², atuante junto ao poder público ${ }^{3}$ e residente neste município.

Diante desses aspectos existenciais, convidamos quatro militantes situados através de suas experiências particulares atreladas à discussão profunda da política pública em nível institucional que aceitaram participar da pesquisa:

1) Colaboradora I - Renata Falzoni. Defende a causa cicloativista em São Paulo desde a década de 1980, atualmente trabalha com conteúdo midiático no site Bike é Legal (BIKE É LEGAL, 2018);

\footnotetext{
1 A Associação dos Ciclistas Urbanos de São Paulo (Ciclocidade) é uma associação que surgiu a partir da reunião de ciclistas urbanos que perceberam a necessidade de uma entidade que ampliasse 0 alcance das ações individuais contribuindo para a construção de políticas públicas (CICLOCIDADE, 2018).

2 Para Zuge Junior (2015), cicloativistas são pessoas que promovem a legitimidade do ciclismo urbano em vista da diferença entre pedalarem espaços fechados ou estradas rurais e nas vias públicas em compartilhamento viário do trânsito com veículos dotados de maior massa com potencial ofensivo, ou seja, na primeira situação, o prazer da atividade física e na segunda, o risco de sofrer um sinistro, mesmo que mínimo em determinadas situações.

3 Para Zuge Junior (2015, p.16-17), o movimento cicloativista em São Paulo está organizado horizontalmente e descentralizado há mais de dez anos, pressionando o poder público junto ao aparato jurisdicional na promoção de políticas de segurança com a implantação de normas jurídicas já existentes e, assim, têm conseguido impor uma série de pautas relativas à gestão de trânsito sabendo articular um discurso que, de certa forma, tornou-se hegemônico na administração municipal.
} 
2) Colaboradora II - Aline Cavalcante. É atual diretora geral da Ciclocidade, também participou do documentário mundial Bikes vs Cars (GERTTEN, 2015);

3) Colaborador III - Daniel Guth. Faz parte da Ciclocidade, inclusive foi produtor do livro $A$ bicicleta no Brasil (SOARES, et al., 2015);

4) Colaborador IV - Thiago Bennichio. Produtor do documentário Sociedade do Automóvel (NUNES; BENNICHIO, 2005), fundador da Ciclocidade, trabalha no Institute for Transportation and Development Policy (INSTITUTO DE POLÍTICAS DE TRANSPORTE E DESENVOLVIMENTO - BRASIL, 2018).

\subsection{Procedimentos para a análise do fenômeno situado}

Para a análise do fenômeno situado, o método fenomenológico está orientado a partir de duas etapas: 1) análise ideográfica e 2) análise nomotética.

Na análise ideográfica, a descrição visa à transformação dos discursos em unidades de significados que expressam as ideias do entrevistado. A análise individual busca tornar visível a ideologia do fenômeno a partir da descrição individual dos sujeitos, que para Martins e Bicudo (1989), é dividida em três momentos:

a) descrição dos discursos numerando as unidades de significado;

b) estas unidades são trabalhadas individualmente para interpretação e expressão analítica do texto como exemplo tácito do fenômeno pesquisado tanto pela atitude, disposição e perspectiva dos significados e;

c) nas transcrições, foi iniciada a redução fenomenológica identificada por um quadro de convergências agrupadas em torno dos discursos analisados.

$\mathrm{Na}$ análise nomotética, é realizada a união das análises ideográficas para formação da matriz nomotética constituída por uma tabela indicativa das generalidades descritas do fenômeno estudado, em que Martins e Bicudo (1989) identificam três momentos:

a) comparação entre os sujeitos pelas unidades de significados interpretadas de todos os discursos analisados quanto às suas convergências e divergências;

b) variação imaginativa que permitiu aproximar-se a uma compreensão geral dos significados para apresentar a estrutura geral discursiva e;

c) formulação explícita de generalidades referente às condições necessárias e constituintes para a compreensão do fenômeno.

\section{RESULTADOS}

$\mathrm{Na}$ análise das entrevistas, observamos que os processos educativos são dinâmicos e estão relacionados concretamente no mundo-vida dos entrevistados.

Passamos à exposição do formato fenomenológico dos discursos de nossos entrevistados, identificando a categoria "Pedalar como direito humano à mobilidade ativa na cidade", constituída de 36 convergências discursivas formadoras destas quatro unidades de significado: 
a) Luta por reconhecimento no direito de fruir o território em bicicleta;

b) Solidariedade com outrem no compartilhamento seguro das vias públicas;

c) Percepção do entorno;

d) Comunicação do movimento cicloativista.

\subsection{Luta por reconhecimento no direito de fruir o território em bicicleta}

Nos processos educativos da unidade de significado "luta por reconhecimento no direito de fruir o território em bicicleta", Renata Falzoni destaca que a bicicleta na via pública passa a ter a devida importância jurídica com o estabelecimento do Código de Trânsito Brasileiro (CTB) (BRASIL, 1998):

A bicicleta no Código de Trânsito Brasileiro passa a adquirir status jurídico nos artigos 21 e 24 inspiram a Política Nacional de Mobilidade Urbana obrigando autoridades competentes de todo o país promoverem a circulação de pedestres e ciclistas em primeiro plano $(\mathrm{l}-14)^{4}$.

Arquiteta de formação, Renata Falzoni é considerada uma militante pioneira que, no começo da década de 1990, promoveu a criação do coletivo Night Bikers Club. Do contexto de atuação, ela nos lembra de uma ação histórica realizada em prol da luta por reconhecimento do ciclismo urbano:

A campanha Bicicleta Brasil foi o reconhecimento da sociedade civil pela inclusão da bicicleta no Código de Trânsito. A aplicação da lei para com os direitos do ciclista é de baixo interesse devido à bicicleta ter baixa representatividade política (I-15).

A campanha "Bicicleta Brasil - Pedalar é um direito" (FALZONI, 2018), realizada em 1999, culminou na manifestação coletiva de ciclistas através de uma viagem de bicicleta de 17 dias de São Paulo a Brasília para entregar uma bicicleta de brinquedo ao então presidente da república Fernando Henrique Cardoso, com a intenção de pressionar as autoridades para o reconhecimento e legitimidade da bicicleta no trânsito urbano, alcançando o seu objetivo. Para Daniel Guth, fotógrafo de formação, apesar da legislação favorecer a mobilidade ativa, a obrigação jurídica limita-se à ocupação espacial viária:

Discutir o direito a mobilidade é um dos pensamentos do ciclista que convive no trânsito, ao contrário da distribuição espacial que destina $79 \%$ do espaço viário público voltado para o carro, mas que representa $30 \%$ dos deslocamentos (III-19).

Também Thiago Bennichio, jornalista de formação, afirma: "A bicicleta é parte da mobilidade urbana na questão do direito ao espaço da cidade consiga ser melhor distribuído e acessível para todos" (IV-18). Esta questão envolve a união de diversos atores sociais, entretanto, não encontra apoio institucional nas decisões políticas por estarem voltadas à visão do motorista:

O poder público contribui diretamente para a desigualdade social no trânsito, principalmente para quem está no transporte coletivo, bicicleta ou pedestre que, da implantação da rede cicloviária chamou a atenção a péssima condição das calçadas. [...] a máquina pública leva tempo para ser mudada em que a infraestrutura cicloviária é o começo da influência no planejamento urbano que encontra resistência interna na Companhia de Engenharia e Tráfego (CET) por

4 Os caracteres romanos correspondem aos entrevistados (I-Renata Falzoni; II-Aline Cavalcante; III-Daniel Guth e IV-Thiago Bennichio) e os números são correspondentes às 36 convergências discursivas extraídas no processo de análise discursiva. 
parte de funcionários, alguns inclusive convencidos pela experiência de que diminuir tempo de semáforo e tirar os ciclistas da rua não é o melhor caminho. Isto ocorre porque a questão é tratada como política de governo diferente de ser uma política de Estado, pois passa a ser prioridade com a institucionalização já que cidades que não tratam a bicicleta como modal de deslocamento na organização institucional, as ações não têm continuidade e fiscalização, principalmente no financiamento das obras que não têm orçamento anual para sua aplicação (IV-7).

Enquanto o poder público detém a autoridade para obras de modificação viária, para Thiago Bennichio, o problema está situado na vontade política no sentido de aplicação da lei em destinar recursos efetivos para infraestrutura cicloviária e, ainda, programas educativos de trânsito com enfoque equitativo:

As obras atuais são feitas a partir de Fundo do Meio Ambiente e Fundo de Desenvolvimento Urbano, formas interessantes de financiamento, mas com a obrigação de ser melhores definidas. Apesar da legislação em São Paulo estar na vanguarda, a nível federal temos um código de trânsito ultrapassado, além do Ministério das Cidades não priorizar a continuidade das políticas públicas principalmente por brigas políticas que influenciam na execução do programa de infraestrutura cicloviária quanto a participação e controle social (IV-10).

Entendemos com os nossos entrevistados este apelo para o uso da bicicleta: ela faz bem à saúde individual e coletiva. Com efeito, o uso particular que fazemos da bicicleta na cidade é uma condição de participação da pessoa como cidadã, no seu direito de ir e vir com segurança. Mas também vemos o ciclismo urbano identificado como saída plausível diante das diretrizes das cartas internacionais de compromisso da Organização Mundial da Saúde (OMS) (THE PAN AMERICAN HEALTH ORGANIZATION, 1978; WORLD HEALTH ORGANIZATION, 1986, 2013). Portanto, é dever dos gestores públicos a responsabilidade na construção da cidadania participativa, incluso do dilema preventivista (AROUCA, 2003), haja vista a obrigação legislativa de formular estratégias de mobilidade urbana e promoção da saúde que priorizem os sujeitos da mobilidade ativa (BRASIL, 2012, 2014).

\subsection{Solidariedade com outrem no compartilhamento seguro das vias públicas}

Quanto aos processos educativos da unidade de significado "solidariedade no compartilhamento seguro das vias públicas", Thiago Bennichio nos indica que a formação do motorista deve estar além da condução de veículos motorizados, ou seja, deve vivenciar a condição do sujeito da mobilidade ativa: "[...] o deslocamento ativo não é só uma questão de educação formal, mas instrução para fora dos muros da escola por aquilo que deveria ser do valor à vida (IV-20)".

Para o discurso cicloativista, há uma complementação inerente entre os conceitos educação e cidadania:

Trazendo obstáculos visuais de ordenação viária para o motorista, cria-se de maneira pedagógica um trânsito mais humanizado como em pequenas cidades europeias há ausência total de regulação (placas de sinalização e semáforos), pois as pessoas têm clareza do respeito à vida. Já no Sudeste Asiático, com a ausência do estado em fornecer transporte público de qualidade, a autorregulação no trânsito é diferente, pois todos os modais (moto, bicicleta, automóvel, caminhão e ônibus) funcionam juntos, não é possível andar em alta velocidade promovendo naturalmente o compartilhamento da mobilidade urbana (III-39). 
Aline Cavalcante, também jornalista de formação, adverte que pedestres, cadeirantes e ciclistas são fundamentais por significarem mais democracia nos deslocamentos urbanos. Ela nos afirma que, embora as pessoas quando pedalam tenham percepções profundas sobre o trânsito, sentem-se vulneráveis ao trânsito acelerado e, na condição social dos valores de gênero, as mulheres encontram ainda mais resistência:

O ciclista, pedestre e cadeirante por viver a condição de cidadão exposto por estarem no tráfego e enxergarem melhor os problemas devido à velocidade lenta de passagem, estão no nível para descobrir o meio diferente do motorista que, pela velocidade de deslocamento, não está disposto a visualizar detalhes. Ser mulher acentua ainda mais o risco pelo estigma social, pois sua vulnerabilidade está atrelada ao discurso do medo perverso que a sociedade impõe evidente (II-9).

O potencial risco de acidentes de trânsito reflete nas estatísticas oficiais na média de 45.000 mortes/ano em cidades brasileiras (OBSERVATÓRIO NACIONAL DE SEGURANÇA VIÁRIA, 2018). Para Thiago Bennichio, muitos desses acidentes deveriam ser qualificados como crimes, porém, a maioria fica impune na justiça devido aos valores da cultura do automóvel estarem impregnados na coisa pública:

A violência generalizada com relação à vida reflete na impunidade dos crimes de trânsito em que qualquer um que mata e tenha dinheiro no Brasil, dificilmente pagará por seu erro, fato que prova a relação público-privado deturpada e protegida pela justiça que serve a interesses privados, também na desconstrução do mundo da propaganda que leva a criança ser individualista e que a escola reproduz (IV20).

Essa relação hostil encarada pelo sujeito da mobilidade ativa envolve cuidados permanentes daqueles que se transladam com o corpo próprio no espaço da cidade. Como a velocidade de deslocamento é um elemento fundamental no processo de segurança viária, Thiago Bennichio acredita que a compreensão da redução consciente da velocidade nas vias públicas passa a ser determinante na relação entre incidência de risco de colisão e acidentes fatais (INTERNATIONAL TRANSPORT FORUM, 2018).

Por querer um trânsito mais humano com o discurso do compartilhamento viário, o movimento começa a influenciar no diálogo sobre o problema da educação no trânsito que se estrutura na velocidade do automóvel nociva à vida humana (IV-7).

Para Aline Cavalcante, na sua formação social junto a outras mulheres ciclistas, a segurança em grupo aumentou durante a criação do coletivo "Pedalinas" (PEDALINAS, 2018):

\begin{abstract}
As Pedalinas surgem do contexto da Bicicletada na criação de um canal de comunicação entre mulheres que sentiam-se incomodadas para descoberta de uma consciência de cidadania. $\mathrm{O}$ ambiente social das Pedalinas agregou em sua formação social como nas vezes em que se reuniam depois dos passeios criando canal de comunicação entre as mulheres que sentiam incomodadas frente ao ambiente hostil e discutiam sobre solidariedade (II-14).
\end{abstract}

Seguindo esse raciocínio, ela relata que sua vida mudou significativamente com 0 ambiente coletivo de mulheres ciclistas, passando a compreender a questão de gênero de forma profunda, o que a fez perceber a importância desse conhecimento no incentivo à concepção de grupos similares em diferentes regiões do país, como, por exemplo, o Bike Anjo, uma rede colaborativa e voluntária de ciclistas urbanos que ajudam as pessoas a utilizar e difundir os benefícios da bicicleta nas cidades (BIKE ANJO, 2018). 


\subsection{Percepção do entorno}

Quanto aos processos educativos da unidade de significado "percepção do entorno", Aline Cavalcante nos descreve a sensação distinta entre pedalar uma bicicleta e como passageira do transporte motorizado:

Após pedalar da minha casa até a universidade, percebi o quão perto era pedalando já que o ônibus dava muitas voltas. A cidade pela ótica do motorista é vista de modo diferente se comparado ao ciclista, pois quando está de carona não se reconhece muitos lugares, como túneis, ao passo que de bicicleta passamos por dentro de bairros para diminuir a distância do trajeto, avistando locais escondidos e pessoas invisíveis que estão na rua e não dentro dos veículos motorizados (Il-11).

As experiências passadas de Aline Cavalcante quanto a acidentes servem de alerta para sua percepção ao pedalar na cidade:

Senti na pele as mazelas de pedalar no trânsito por já ter tido acidentes e tive de colocar pinos, sinal de cicatrizes é uma marca que indica erros cometidos, mas necessários para 0 aprendizado não apenas teórico, mas pela experiência real na construção do ser que influencia os valores e a ética no papel social fazendo com o que corpo se torne mais sensível frente aos estímulos diários, essencial para autocrítica em perceber o mundo da rua (II-4).

Daniel Guth entende as distintas visões complementares na compreensão do trânsito: "[...] quando fui morar próximo ao centro, passei a ter contato mais próximo da cidade entendendo que as distâncias são acessíveis para modos não motorizados (III-8)".

Devido às pessoas nas cidades estarem cada vez mais isoladas, aproximá-las pela bicicleta ajuda em sua reorganização porque elas começam a perceber que no lugar de carros estacionados poderia ter uma calçada maior ou ciclovia, como também do transporte público cumprir seu papel de forma plena, o deslocamento do pedestre e do ciclista muda paradigmas de tempo e velocidade a ponto de entender melhor as distâncias porque o tempo do motorista não é contínuo, já que dirigindo acelera e freia, ao contrário da velocidade da bicicleta ser contínua (IV-29)

Concordamos com Paulo Saldiva, ciclista urbano e médico patologista da Universidade de São Paulo (USP), ao mencionar a ordem ambiental como ponto fundamental no trato da coisa pública, afirmando que os órgãos ambientais estão despreparados para lidar com as questões de saúde em razão de atenderem apenas os ecossistemas de áreas remotas, pois "os órgãos de saúde não incorporaram a questão ambiental no rol de atribuições primordiais e neste vácuo, gerado pela falta de uma abordagem ecossistêmica da saúde humana, surgem condições para a deterioração do ambiente urbano em detrimento da qualidade de vida" (SALDIVA, 2010, p.20).

\subsection{Comunicação do movimento cicloativista}

Em relação aos processos educativos da unidade de significado "comunicação do movimento cicloativista", Daniel Guth cita o Critical Mass (CARLSSON; ELLIOT; CAMARENA, 2012), também chamado no Brasil "Bicicletada - Massa Crítica". Este evento realizado mensalmente em mais de 330 cidades ao redor do mundo (MASSA CRÍTICA - POA, 2018), do qual os entrevistados também participam, tem a função de desenvolver agregação coletiva de 
ciclistas para ocupação das ruas interrompendo o fluxo de veículos. Essa organização cidadã tornou visível a condição vulnerável dos ciclistas urbanos.

Da idealização e realização do evento, surge com o passar dos encontros a Ciclocidade como manifestação coletiva para formação de um canal de comunicação formal para reivindicação institucionalizada, o reconhecimento do pedalar como direito humano à mobilidade ativa na cidade de São Paulo:

O movimento horizontal da Bicicletada-Massa Crítica contribui para a autonomia da consciência organizada na qual a Ciclocidade contempla canais diretos de comunicação na Câmara dos Vereadores para democratização do debate público no contexto de que poucos têm conhecimento acumulado, por isso movimento social é intenso pelo acúmulo histórico de reivindicações por pessoas com conhecimento de causa devido à maturação das mobilizações (III-38).

Durante o período de comunicação com representantes do governo, Daniel Guth afirma: "Percebendo que o gestor público não está atualizado sobre a dimensão histórica e política da bicicleta, foi necessário referenciar informações para descobrir quem era 0 interlocutor e 0 grau de conhecimento sobre a temática (III-27)". Ele prossegue seu argumento ressaltando a necessidade pedagógica:

Em outros países a discussão avança para tornar o espaço público mais atraente para as pessoas, diferente do nosso país que, em levantamento da Associação Nacional de Transporte Público (ANTP), mostra que o orçamento para a mobilidade urbana está voltado para a promoção do transporte motorizado individual, independente de estudos acadêmicos provarem a ineficiência na perpetuação desse sistema, o que se deve à não compreensão da estrutura da mobilidade humana (III-16).

O entrevistado observa que o uso e a ocupação do solo servem aos interesses econômicos, gerando efeitos perversos no campo da mobilidade urbana. Uma possível solução está na melhoria da infraestrutura cicloviária para propiciar o uso cotidiano da bicicleta com segurança e dignidade, sendo essencial a mobilização dos ciclistas urbanos de cada zona da cidade para convergência de interesses:

O prefeito que ocupar a função de mandatário tem a obrigação de compreender esse processo histórico de construção coletiva e que, caso haja uma resistência, a mobilização será imediata como quando o movimento colocou 7000 pessoas de bicicleta na Avenida Paulista, mostrando a maturidade política e clareza de discurso nos argumentos, o que está evidente na participação social no Conselho Municipal de Trânsito e Transporte, Conselho Municipal de Política Urbana e Conselho das Cidades (III-39).

Apesar da recente representação em conselhos de participação, Thiago Bennichio, com sua experiência anterior na Ciclocidade e, atualmente, na organização internacional do ITDP, visualiza outras explicações para a (des)organização da mobilidade ativa:

A máquina pública leva tempo para ser mudada em que a infraestrutura cicloviária é o começo da influência no planejamento urbano que encontra resistência interna na CET pelos funcionários. Alguns inclusive convencidos pela experiência de que diminuir tempo de semáforo e tirar os ciclistas da rua não é o melhor caminho. Isto ocorre porque a questão é tratada como política de governo diferente de ser uma política de estado, pois passa a ser prioridade com a institucionalização, já que cidades que não tratam a bicicleta como modal de deslocamento na organização institucional, as ações não têm continuidade e fiscalização, principalmente no financiamento das obras que não têm orçamento anual para sua aplicação (IV-7). 
Thiago Bennichio nos atenta para a linguagem artística do movimento cicloativista que se mostra incisiva quanto à dimensão humanizadora da bicicleta:

A bicicleta com sua velocidade humana é uma antítese poética à velocidade mecânica do automóvel organizada em primeira instância no entendimento da mobilidade. A ruptura urbana é condição para pensar como a propriedade privada dificulta discussões sobre a construção do território sem ponderações à equidade social (IV-32).

\section{CONSIDERAÇÕES FINAIS}

Partindo do objetivo da pesquisa em compreender os processos educativos do ciclismo urbano decorrentes da prática social do cicloativismo atuante na cidade de São Paulo, destaque para duas outras metrópoles latino-americanas. A cidade de Bogotá (Colômbia) investe na construção de infraestrutura cicloviária e na restrição parcial do tráfego viário aos finais de semana para promoção de atividades físicas e recreativas para a população através do Programa Ciclovía do Instituto Distrital de Recreación y Deporte (IDRD) (ALCADIA MAYOR DE BOGOTÁ, 2018)5. E a cidade de Santiago (Chile), com as propostas de caráter territorial Ciudad Vida (SAGARIS, 2014) e da representação política do Bicicultura (BICICULTURA, 2018). No primeiro caso, a gestão da política pública na organização institucional e, no segundo caso, a participação social representativa. Esses exemplos mostram os avanços na mobilidade ativa por bicicleta no continente sul-americano e nos guiam para a noção de responsabilidade da cidadania através da articulação de valores sociais entre a sociedade civil e o poder público para a organização democrática.

Afirmamos no território paulistano que a categoria "Pedalar como direito humano à mobilidade ativa na cidade" resultado das convergências discursivas, representa o fenômeno ciclismo urbano nos processos educativos vivenciados pela prática social do cicloativismo quanto ao direito de fruir o território em bicicleta, no compartilhamento seguro das vias públicas, na percepção do entorno e na comunicação entre cicloativistas.

Entre as legítimas reivindicações por melhores condições de segurança viária para a mobilidade ativa na cidade de São Paulo, entendemos que a restrição entre 30 e 50km/h nos centros urbanos para a velocidade do transporte motorizado e a retirada substancial de vagas para estacionamentos de automóveis, com a consequente implementação de ciclovias e ciclofaixas (CONCELLO DE PONTEVEDRA, 2017) e a criação de espaços públicos de convivência, como, por exemplo, a "Praça de Bolso do Ciclista", na cidade de Curitiba (Paraná) (SANTANA; RECHIA; RODRIGUES, 2017), são possíveis estratégias de impacto positivo na promoção da cultura de bicicleta no Brasil. Além disso, acreditamos em uma saída legislativa envolvendo processos educativos de ensino-aprendizagem com o uso da bicicleta como veículo de transporte: a vivência de pedalar no trânsito como um estágio obrigatório ao pleitear a Carteira Nacional de Habilitação $(\mathrm{CNH})$ auxiliará ao futuro condutor, a ótima internalização das regras com possíveis benefícios para o campo da mobilidade urbana que a prática em si gera no cuidado para com o outro que trafega no espaço viário.

5 Em 2005, foi realizada em Bogotá, Colômbia, a Primera Conferencia Internacional sobre Ciclovías Recreativas, iniciativa conjunta entre a Organização Pan-americana de Saúde (OPS/OMS), Centro de Control y Prevención de Enfermedades (CDC) e comunidade promotora da mobilidade não motorizada com a missão de reunir organizações da sociedade civil, instituições municipais, estatais e internacionais de todo o continente americano para fomentar intercâmbio de experiências, além de facilitar o desenvolvimento de novos programas. 0 encontro resultou na Declaración de Bogotá, firmada por 16 institutos promotores que, quatro anos depois, transformaram-se na Red de Ciclovías Recreativas de las Américas (RED CRA, 2018). 
Concluímos que, apesar das reivindicações do movimento cicloativista por melhores condições para o ciclismo urbano, grande parte dos ciclistas urbanos deixam de alcançar 0 âmbito político por desconhecerem o aspecto simbólico do efeito blasé (SIMMEL, 2005). Diante dessa situação desfavorável, compreendemos que a discussão proposta em audiências públicas de implantação da infraestrutura cicloviária influencia positivamente tanto na representação institucional como no enfrentamento à indiferença coletiva (de motoristas) aos ciclistas urbanos.

\section{REFERÊNCIAS}

ALCADÍA MAYOR DE BOGOTÁ. Programa Ciclovía. Disponível em: <https://www.idrd.gov.co/sitio/ idrd/content/la-ciclovia-bogotana>. Acesso em: 03 abr. 2018.

AROUCA, Sérgio. 0 dilema preventivista: contribuição para a compreensão e crítica da medicina preventiva. São Paulo: Ed. UNESP; Rio de Janeiro: Ed. FIOCRUZ, 2003.

BICICULTURA. Disponível em: <www.bicicultura.cl>. Acesso em: 02 abr. 2018.

BICUDO, Maria Aparecida Viggiani; ESPOSITO, Vitória Helena Cunha. Joel Martins... um seminário avançado em fenomenologia. São Paulo: Educ, 1997.

BICUDO, Maria Aparecida Viggiani. Pesquisa qualitativa segundo a visão fenomenológica. São Paulo: Cortez, 2011.

BIKE ANJO. Relatório parcial de projeto Programa Escola Bike Anjo São Paulo. Disponível em: <https://bikeanjo.files.wordpress.com/2017/04/relatc3b3rio-de-projeto-bike-anjo-programa-ebasp-2016-17.pdf>. Acesso em: 01 abr. 2018.

BIKE É LEGAL. Tudo sobre bicicleta e mobilidade urbana. Disponível em: <https://bikeelegal. com/>. Acesso em: 16 set. 2018.

BRASIL. Código de Trânsito Brasileiro (CTB). Lei n. 9.503, 23 de setembro de 1997. Brasília, DF, 1998. Disponível em: <http://www.planalto.gov.br/Ccivil 03/leis/L9503.htm>. Acesso em: 10 fev. 2018.

BRASIL. Política Nacional de Mobilidade Urbana (PNMU). Lei no 12.587, de 3 de janeiro de 2012. Brasília, DF, 2012. Disponível em: <http://www.planalto.gov.br/ccivil 03/ ato2011-2014/2012/lei/ 112587.htm>. Acesso em: 30 nov. 2017.

BRASIL. Política Nacional de Promoção da Saúde (PNPS). Portaria no 2446, de 11 de novembro de 2014. Brasília, DF, 2014. Disponível em: <http://bvsms.saude.gov.br/bvs/publicacoes/politica nacional promocao saude 3ed.pdf>. Acesso em: 12 ago. 2017.

BRASIL. Conselho Nacional de Saúde. Resolução n. 466, de 12 de dezembro de 2012a. Diário Oficial da União, Poder Legislativo, Brasília, DF, 13 jun. 2013. Disponível em: <www.planalto.gov.brl ccivil/Decreto-Lei/1965-1988/Del0464.htm>. Acesso em: 03 maio 2018.

CARLSSON, Chris; ELLIOT, Lisa Ruth; CAMARENA, Adriana. Shift Happens! Critical Mass at 20. São Francisco: Full Enjoyment Books, 2012.

CICLOCIDADE. Associação dos Ciclistas Urbanos de São Paulo. Disponível em: <www. ciclocidade.org.br >. Acesso em: 01 abr. 2018. 
CICLOVÍAS RECREATIVAS. Red de Ciclovías Recreativas de las Américas. Disponível em: <http:// cicloviasrecreativas.esy.es/red/>. Acesso em: 16 set. 2018.

COLVILLE-ANDERSEN, Mikael. Copenhagenize: The Definitive Guide to Global Bicycle Urbanism. Washington: Island Press, 2018.

CONCELLO DE PONTEVEDRA. Menos coches, más ciudad. Pontevedra: Alcaldía de Pontevedra, 2017. Disponível em: <http://www.pontevedra.gal/publicacions/menos-coches-cast/files/assets/ common/downloads/publication.pdf. $>$ Acesso em: 01 abr. 2018.

FALZONI, Renata. Bicicleta Brasil - Pedalar é um direito. Documentário, 2018. Disponível em: $<$ https://www.youtube.com/watch?v=MRadb3 guDk\&t=2s $>$. Acesso em: 03 maio 2018.

FREIRE, Paulo; FAÚNDEZ, Antônio. Por una pedagogia de la pregunta: Critica a una educación basada en preguntas inexistentes. Barcelona: Siglo XXI, 2012.

GAMBETA, Wilson Roberto. A bola rolou: o velódromo paulista e os espetáculos de futebol (1895/1916). 2013. 408f. Tese (Doutorado) - Programa de Pós-Graduação em História Social, USP, São Paulo, 2013.

GERTTEN, Fredik. Bikes vs Cars. [Documentário], 2015. Disponível em: <http://www.bikes-vs-cars. com/>. Acesso em: 06 mar. 2018.

INSTITUTO DE POLÍTICAS DE TRANSPORTE E DESENVOLVIMENTO BRASIL. Rio de Janeiro, 2018. Disponível em: <http://itdpbrasil.org.brl>. Acesso em: 03 maio 2018.

INTERNATIONAL TRANSPORT FORUM. Speed and Crash Risk. Paris: International Traffic Safety Data and Analysis Group. 2018. Disponível em: <https:/www.itf-oecd.org/sites/default/files/docs/ speed-crash-risk.pdf >. Acesso em: 30 mar. 2018.

MARTINS, Joel; BICUDO, Maria Aparecida Viggini. Pesquisa qualitativa em psicologia: fundamentos e recursos básicos. São Paulo: EDUC, 1989.

MASSA CRÍTICA - POA. Pedalando por um mundo mais respirável. Disponível em: <https:// massacriticapoa.wordpress.com/>. Acesso em: 03 maio 2018.

NUNES, Branca; BENNICHIO, Thiago. Sociedade do Automóvel. [Documentário], 2005. Disponível em: <https://www.youtube.com/watch?v=4eWvSwzkidE>. Acesso em: 02 abr. 2018.

OBSERVATÓRIO NACIONAL DE SEGURANÇA VIÁRIA. Indaiatuba, SP, 2018. Disponível em: $<$ http://iris.onsv.org.br/iris-beta/\#/stats/maps>. Acesso em: 28 abr. 2018.

OLIVEIRA, Maria Waldenez et al. Processos educativos em práticas sociais: reflexões teóricas e metodológicas sobre pesquisa educacional em espaços sociais. In: OLIVEIRA, Maria Waldenez; SOUSA, Fabiana (Org.). Processos educativos em práticas sociais: pesquisas em educação. São Carlos: EdUFSCar, 2014.

THE PAN AMERICAN HEALTH ORGANIZATION PROMOTING HEALTH IN THE AMERICAS. Declaração de Alma-Ata: Conferencia Internacional sobre Atención Primaria de Salud, AlmaAta, URSS, 6-12 de sept. 1978. Disponível em <http://www.paho.org/hq/index.php?option=com docman\&task=doc view\&gid=19004\&ltemid=270\&lang=en>. Acesso em: 10 fev. 2018.

PEDALINAS. Coletivo Feminino de Ciclistas. Disponível em: <https://pedalinas.wordpress.com/>. Acesso em: 03 maio 2018. 
SAGARIS, Lake. Citizen participation for sustainable transport: the case "Living City" in Santiago, Chile (1997-2012). Journal of Transport Geography, v.41, p. 74-83, 2014.

SALDIVA, Paulo Hilário Nascimento. O homem e o meio ambiente urbano. In: VORMITTAG, Evangelina; SALDIVA, Paulo. (Org.) Meio ambiente e saúde: o desafio das metrópoles. São Paulo: Instituto Saúde e Sustentabilidade, 2010.

SANTANA, Daniella Tschöke; RECHIA, Simone; RODRIGUES, Emília Amélia Pinto Costa. As Brechas da Cidade: a Praça de Bolso do Ciclista da Cidade de Curitiba, Paraná. Movimento, v. 23, n.1, p. 311-324, 2017.

SÃO PAULO. Plano Diretor Estratégico (PDE). Lei no 16.050, de 31 de julho de 2014. Disponível em: $<$ http://gestaourbana.prefeitura.sp.gov.br/arquivos/PDE lei final aprovada/TEXTO/2014-07-31\%20 -\%20LEI\%2016050\%20-\%20PLANO\%20DIRETOR\%20ESTRAT\%C3\%89GICO.pdf>. Acesso em: 28 mar. 2018.

SÃO PAULO. Plano de Mobilidade Urbana (PlanMob). Secretaria Municipal de Transportes: São Paulo Transporte S. A. - SPTrans, Companhia de Engenharia de Tráfego - CET, 2015. Disponível em: <http://www.prefeitura.sp.gov.br/cidade/secretarias/upload/chamadas/planmobsp v072 1455546429.pdf >. Acesso em: 27 abr. 2018.

SIMMEL, Georg. As grandes cidades e a vida no espírito. Mana, v. 11, n.2, p.577-591, 2005.

SOARES, André Geraldo et al. (Orgs). A bicicleta no Brasil. São Paulo: Aliança Bike, Bicicleta para Todos, Bike Anjo e UCB, 2015. Disponível em: <http://www.uniaodeciclistas.org.br/biblioteca/adquiralivro/>. Acesso em: 03 maio 2018.

SOUZA, Yuri Vasquez. Quando as rodas conquistam a cidade: cultura, tensões, conflitos e ações na prática do ciclismo em São Paulo. 2016, 149f. Dissertação (Mestrado) - Programa de PósGraduação em História, PUC, São Paulo, 2016.

WORLD HEALTH ORGANIZATION. The Ottawa Charter for Health Promotion. The first International Conference on Health Promotion. Ottawa, 21 Nov. 1986. Disponível em: <http://www.who.int/ healthpromotion/conferences/previous/ottawa/en> Acesso em: 08 abr. 2018.

WORLD HEALTH ORGANIZATION. The Helsinki Statement on Health in All Policies. In: GLOBAL CONFERENCE ON HEALTH PROMOTION.8. Geneva, 2013. Disponível em: <http://www.who.int/ healthpromotion/conferences/8gchp/statement 2013/en/>. Acesso em: 28 mar. 2018.

ZUGE JUNIOR, Odir. Cicloativismo paulistano: uma investigação jurídico-fenomenológica. 2015. 107f. Tese (Doutorado) - Programa de Pós-Graduação em Direito. USP, São Paulo, 2015. 


\section{Apoio:}

o presente trabalho foi realizado com apoio da Coordenação de Aperfeiçoamento de Pessoal de Nível Superior - Brasil (CAPES) - Código de Financiamento 001.

This study was financed in part by the Coordenação de Aperfeiçoamento de Pessoal de Nível Superior - Brasil (CAPES) - Finance Code 001. 